\title{
Molecular and evolutionary relationships among enteric bacteria
}

\author{
JefFrey G. LaWrence, Howard Ochman and Daniel L. HartL* \\ Department of Genetics, Box 8232, Washington University School of Medicine, St Louis, MO 63110, USA
}

(Received 19 November 1990; revised 3 April 1991; accepted 10 April 1991)

\begin{abstract}
Classification of bacterial species into genera has traditionally relied upon variation in phenotypic characteristics. However, these phenotypes often have a multifactorial genetic basis, making unambiguous taxonomic placement of new species difficult. By designing evolutionarily conserved oligonucleotide primers, it is possible to amplify homologous regions of genes in diverse taxa using the polymerase chain reaction and determine their nucleotide sequences. We have constructed a phylogeny of some enteric bacteria, including five species classified as members of the genus Escherichia, based on nucleotide sequence variation at the loci encoding glyceraldehyde-3-phosphate dehydrogenase and outer membrane protein $3 \mathrm{~A}$, and compared this genealogy with the relationships inferred by biotyping. The DNA sequences of these genes defined congruent and robust phylogenetic trees indicating that they are an accurate reflection of the evolutionary history of the bacterial species. The five species of Escherichia were found to be distantly related and, contrary to their placement in the same genus, do not form a monophyletic group. These data provide a framework which allows the relationships of additional species of enteric bacteria to be inferred. These procedures have general applicability for analysis of the classification, evolution, and epidemiology of bacterial taxa.
\end{abstract}

\section{Introduction}

Classification of bacteria into species, genera and higher categories has been a historically enigmatic issue. While an abundance of phenotypic characters allows rigorous taxonomic treatment of many eukaryotic phyla, few readily available characters aid in the unambiguous classification of bacterial strains. Accurate classification of bacterial species is necessary for clinical and epidemiological studies, and a taxonomy which accurately reflects the evolutionary relationships among species provides a framework for elucidating the evolution of genes, gene families and metabolic pathways, for interpreting the distribution of extrachromosomal elements, and for inferring potential transfer of genetic material between species.

Traditionally, metabolic characteristics, such as the ability to metabolize certain carbon sources, or the production or catabolism of various biochemical compounds, have been used to classify bacterial strains into

Abbreviations: CAI, codon adaptation index; GAPDH, glyceraldehyde-3-phosphate dehydrogenase.

The nucleotide sequence data reported in this paper have been submitted to GenBank and have been assigned the accession numbers M63343-M63374. species and species groups on purely phenetic grounds. More recently, total DNA relatedness has been proposed as a more reliable method for grouping conspecific bacterial strains (e.g. Brenner, 1978). While either method can define species boundaries, criteria for grouping species into genera are less clear. Biochemical and metabolic phenotypes often have a multifactorial genetic basis, that is, multiple genes are responsible for their expression. Owing to convergent evolutionary events in distantly related lineages, these characters cannot be used reliably for a hierarchical grouping of species in a cladistic manner (one based on the identification of shared derived characteristics). DNA hybridization methods, while sufficient to define the range of variation expected for a bacterial species, do not provide an accurate assessment of relatedness allowing the grouping of congeneric species, and the placement of species into genera has relied upon characteristic metabolic features which are neither rigorously defined nor statistically testable (Brenner et al., 1978, 1980).

To eliminate such problems in the classification of bacterial species, their genetic relationships must be assessed beyond the accuracy allowed by total DNA relatedness. The DNA sequences of slowly evolving loci can provide the information necessary to unambiguously classify taxa above the species level and avoid the 
inconsistencies intrinsic to epistatic phenotypic traits. The necessary DNA sequences are readily obtainable by the polymerase chain reaction (PCR) (Saiki et al., 1985, 1988). Classification based on patterns of nucleotide substitutions allows statistical testing of the inferred evolutionary relationships, while statistical tests of phylogenies based on weighted phenotypic characters are either unavailable or unreliable. Escherichia coli is one of the most intensively studied organisms in terms of its genetics, physiology and molecular biology. Since 1973, an additional four species of Escherichia have been described: Escherichia blattae (Burgess et al., 1973), Escherichia fergusonii (Farmer et al., 1985), Escherichia hermannii (Brenner et al., 1982a) and Escherichia vulneris (Brenner et al., 1982b). With the exception of E. blattae, DNA relatedness was used to classify each group as a distinct species. The classification of all four species in this genus was based upon overall phenotypic similarity, and each exhibited a combination of metabolic characters atypical for other genera.

By designing oligonucleotide primers homologous to evolutionarily conserved sequences, it is possible to amplify homologous regions of ubiquitous genes in diverse taxa using PCR and to determine their nucleotide sequences (Kocher et al., 1989; Taylor \& Kreitman, 1989). We have determined the DNA sequences of major portions of the gap and ompA genes, which encode glyceraldehyde-3-phosphate dehydrogenase (GAPDH) and outer membrane protein $3 \mathrm{~A}$, respectively, of strains representative of eleven species of enteric bacteria, including the five species of Escherichia. The inferred genetic relationships were used to test the correlation of the phenotypic characters defining the genus Escherichia.

\section{Methods}

Bacterial strains and genetic loci. Chromosomal DNA was isolated from the eighteen strains of enteric bacteria listed in Table 1, by methods described previously (Sawyer et al., 1987). The gap locus encodes GAPDH and is located at $39.3 \mathrm{~min}$ on the Escherichia coli linkage map (Bachmann, 1990). The ompA locus encodes outer membrane protein $3 \mathrm{~A}$ and is located at $21.8 \mathrm{~min}$ on the linkage map (Bachmann, 1990). Sequences homologous to the E. coligap and ompA loci were verified in each of the strains listed in Table 1 by Southern blot genomic DNA hybridization analysis (data not shown). Using the published nucleotide sequences of the gap locus from E. loci, Bacillus stearothermophilus and eukaryotes (Branlant \& Branlant, 1985; Branlant et al., 1989; Stone et al., 1985), and of the ompA locus from E. coli and Serratia marcescens (Beck \& Bremer, 1980; Braun \& Cole, 1984), oligonucleotide primers were synthesized complementary to highly conserved regions of these genes containing low codon redundancy. These primers allow the PCR amplification of a $906 \mathrm{bp}$ fragment encompassing $91 \%$ of the gap locus and a 711 bp fragment spanning $68 \%$ of the ompA locus. The gap oligonucleotides were: dACTATCAAAGTAGGTATCAA, forward strand at nucleotide 4; dGGATTTGGCCGCATCGGCCG, forward strand at nucleotide 25;
Table 1. Strains analysed for gap and ompA sequences

\begin{tabular}{|c|c|c|c|c|}
\hline \multirow[b]{2}{*}{ Strain } & \multicolumn{2}{|c|}{ ompA } & \multicolumn{2}{|c|}{ gap } \\
\hline & $\mathrm{CAI}^{*}$ & $\begin{array}{l}\mathrm{Mol} \% \\
\mathrm{G}+\mathrm{C}\end{array}$ & $\mathrm{CAI}^{*}$ & $\begin{array}{l}\mathrm{Mol} \% \\
\mathrm{G}+\mathrm{C}\end{array}$ \\
\hline Citrobacter freundii $\mathrm{OS} 60 \dagger$ & 0.76 & $51 \cdot 8$ & 0.82 & $49 \cdot 6$ \\
\hline Enterobacter aerogenes $\mathrm{E} 482 \ddagger$ & 0.73 & $53 \cdot 6$ & 0.75 & $50 \cdot 2$ \\
\hline $\begin{array}{l}\text { Escherichia blattae ATCC } 29907^{\mathrm{T}} \\
\text { E. blattae ATCC } 33429 \\
\text { E. blattae ATCC } 33430\end{array}$ & 0.81 & $54 \cdot 5$ & 0.80 & 52.4 \\
\hline Escherichia coli $\mathrm{K} 12 \S$ & 0.79 & $54 \cdot 7$ & 0.83 & $50 \cdot 1$ \\
\hline $\begin{array}{l}\text { Escherichia fergusonii ATCC } 35469^{\mathrm{T}} \\
\text { E. fergusonii ATCC } 35471 \\
\text { E. fergusonii ATCC } 35472\end{array}$ & 0.82 & $53 \cdot 5$ & 0.83 & $49 \cdot 4$ \\
\hline $\begin{array}{l}\text { Escherichia hermannii ATCC } 33650^{(\mathrm{T})} \\
\text { E. hermannii ATCC } 33652\end{array}$ & 0.81 & $53 \cdot 1$ & 0.83 & $50 \cdot 5$ \\
\hline Escherichia vulneris ATCC $29943^{\mathrm{T}}$ & 0.81 & $55 \cdot 6$ & 0.83 & 51.7 \\
\hline $\begin{array}{l}\text { E. vulneris ATCC } 33821 \\
\text { E. vulneris ATCC } 33822\end{array}$ & 0.77 & 53.9 & 0.82 & $51 \cdot 2$ \\
\hline Klebsiella pneumoniae LD119\| & 0.82 & $56 \cdot 5$ & $0 \cdot 82$ & $52 \cdot 6$ \\
\hline Salmonella typhimurium $\mathrm{LT} 2 \S$ & 0.74 & $54 \cdot 2$ & $0 \cdot 78$ & $50 \cdot 8$ \\
\hline Serratia marcescens ATCC $13880^{\mathrm{T}}$ & 0.73 & $53 \cdot 5$ & 0.69 & $53 \cdot 3$ \\
\hline Serratia odorifera ATCC $3307^{\mathrm{T}}$ & 0.73 & $53 \cdot 7$ & 0.69 & $52 \cdot 4$ \\
\hline
\end{tabular}

* Codon adaptation index (Sharp \& $\mathrm{Li}, 1987 b$ ).

† Clinical isolate (Bergström et al., 1984).

$\ddagger$ Clinical isolate from B. Wiedermann, Bonn, Germany.

$\S$ Laboratory collection.

\|Clinical isolate from S. Normark, Östersund, Sweden.

T Type strain.

dCCGAACTCGTTGTCGTACCA, reverse strand at nucleotide 910 The $o m p A$ oligonucleotides were: dAAAGCTCAGGGCGTTCA, forward strand at nucleotide 280; dGCGGCTGAGTTACAACGTCTTT, reverse strand at nucleotide 1031 .

Template preparation. PCR (Saiki et al., 1985, 1988) was performed in a buffer containing $50 \mathrm{~mm}-\mathrm{KCl}, 10 \mathrm{mM}-\mathrm{Tris}(\mathrm{pH} 8.4), 2.5 \mathrm{~mm}-\mathrm{MgCl}_{2}$, $0.01 \%$ gelatin, $800 \mu \mathrm{M}-\mathrm{dNTP}, 25 \mathrm{U}$ Taq polymerase $\mathrm{ml}^{-1}$ (Cetus), $2 \mathrm{ng}$ of each oligonucleotide primer $\mu \mathrm{I}^{-1}$ and $10-50 \mathrm{ng}$ chromosomal DNA. The amplified sample was size-fractionated by agarose gel electrophoresis and DNA fragments of the appropriate size were isolated on Schleicher and Schuell NA45 DEAE paper. The paper-bound DNA was briefly washed in a buffer [ $150 \mathrm{mM}-\mathrm{NaCl}, 50 \mathrm{~mm}$-Tris $(\mathrm{pH} 8.0)$, $10 \mathrm{~mm}$-EDTA] at room temperature and eluted in a solution of $1 \mathrm{M}$ $\mathrm{NaCl}, 50 \mathrm{~mm}$-Tris (pH 8.0), $10 \mathrm{~mm}$-EDTA at $68^{\circ} \mathrm{C}$ for $30 \mathrm{~min}$. The DNA was serially extracted with buffer-saturated phenol and chloroform/isoamyl alcohol $(24: 1, \mathrm{v} / \mathrm{v})$, and precipitated with $2 \cdot 5$ vols $100 \%$ ethanol in the presence of a linear polyacrylamide carrier (Galliard \& Strauss, 1990). DNA was recovered by centrifugation, rinsed with $70 \%(\mathrm{v} / \mathrm{v})$ ethanol to remove salts and dried in a vacuum desiccator prior to resuspension in $10 \mathrm{~mm}$-Tris, $1 \mathrm{~mm}$-EDTA.

DNA sequencing. Each DNA template (100 ng) was denatured in $0.2 \mathrm{M}-\mathrm{NaOH}$ for $5 \mathrm{~min}$, neutralized by the addition of one-third vol. $3 \mathrm{M}$-potassium acetate ( $\mathrm{pH} \mathrm{4.6)}$ ) and precipitated with 2.5 vols of $100 \%$ ethanol in the presence of additional polyacrylamide carrier. Following incubation at $-20^{\circ} \mathrm{C}$ for $30 \mathrm{~min}$, DNA was recovered by centrifugation as described above and sequenced with Sequenase 2.0 (United States Biochemicals) according to the manufacturer's instructions. The sequences of both strands of each DNA template were determined using internal oligonucleotide primers (sequences determined by these methods yield over $99.9 \%$ accuracy). DNA sequence analysis was facilitated by the PAUP (version 2.4, D. Swofford) and MacClade 
(version 2.1, W. Maddison \& D. Maddison) program packages. Statistics applied in creating and testing phylogenies are detailed below.

\section{Results and Discussion}

Ribosomal RNA sequences have proved useful in discerning the relationships between distantly related taxa of eubacteria, archaeobacteria and eukaryotes (e.g. Woese, 1987). However, the slow rates of evolution of these molecules preclude their use in the fine-scale phylogenetic positioning of taxa; the 16S rRNA sequence differs by only $2-3 \%$ between $E$. coli and Salmonella typhimurium (C. Woese, personal communication). While substitutions at this locus provide a powerful tool for discerning the relationships between very distantly related taxa, they do not supply adequate information for the elucidation of relationships between more closely related taxa, e.g. members of the same genus.

In contrast, typical protein-encoding genes evolve at a relatively rapid rate. The synonymous sites (positions at which substitutions would not alter the amino acid composition of the protein) differ by $50-60 \%$ between E. coli and Sal. typhimurium (Ochman \& Wilson, 1988; Sharp \& Li, 1987a). Assuming a random accumulation of substitutions at these sites, this level of divergence limits their utility in phylogenetic reconstruction of higher taxa because most sites are assumed to have mutated at least once and would therefore contain ambiguous phylogenetic information.

The bacterial genome contains a class of highly expressed genes which experience selective pressures on codon choice, reflected in high codon usage bias (Sharp $\& \mathrm{Li}, 1987 b$ ). Not surprisingly these genes evolve more slowly at synonymous sites (Sharp \& Li, 1987a). The gap and $o m p A$ loci are highly expressed genes which exhibit a high degree of codon bias (Table 1). Between E. coli and Sal. typhimurium, these genes differ by 16 and $20 \%$ at synonymous sites, respectively. This level of nucleotide divergence allows an adequate estimation of the genetic relationships between closely related species, while minimizing convergent evolutionary events. Our data indicate that DNA sequences of slowly evolving genes such as gap and $o m p A$ may be useful in determining the taxonomic placement of novel isolates, as well as in resolving the phylogenetic relationships amongst established taxa.

The nucleotide sequences of gap and ompA are the first to be obtained from all the representative enteric species subsequent to the divergence of the genus Serratia. The aligned sequences of portions of the gap and ompA loci from eighteen strains of enteric bacteria are presented in
Table 2. Nucleotide sequence differences between strains within species

\begin{tabular}{|c|c|c|c|}
\hline \multirow[b]{2}{*}{ Strain* } & \multirow{2}{*}{$\begin{array}{c}\text { gap } \\
\text { Changes }\end{array}$} & \multicolumn{2}{|c|}{$o m p A$} \\
\hline & & Changes & Deletions \\
\hline \multicolumn{4}{|c|}{ Escherichia blattae } \\
\hline $29907 / 33429$ & 3 & 12 & 0 \\
\hline $29907 / 33430$ & 2 & 12 & 1 \\
\hline $33429 / 33430$ & 3 & 8 & 1 \\
\hline \multicolumn{4}{|c|}{ Escherichia fergusonii } \\
\hline $35469 / 35471$ & 2 & 1 & 0 \\
\hline $35469 / 35472$ & 1 & 1 & 0 \\
\hline $35471 / 35472$ & 1 & 0 & 0 \\
\hline \multicolumn{4}{|c|}{ Escherichia hermannii } \\
\hline $33650 / 33652$ & 3 & 1 & 0 \\
\hline \multicolumn{4}{|c|}{ Escherichia vulneris } \\
\hline $29943 / 33821$ & 71 & 94 & 3 \\
\hline 29943/33822 & 73 & 95 & 3 \\
\hline $33821 / 33822$ & 5 & 7 & 0 \\
\hline
\end{tabular}

* ATCC numbers from Table 1.

Fig. 1. The ompA sequences from E. coli, Sal. typhimurium and Serr. marcescens and the gap sequence from $E$. coli agree well with previously determined sequences (Beck \& Bremer, 1980; Branlant \& Branlant, 1985; Braun \& Cole, 1984; Freudl \& Cole, 1983). The G+C contents of the sequences range from 49 to $56 \mathrm{~mol} \%$ (Table 1) and, for the most part, reflect the overall genomic $\mathrm{G}+\mathrm{C}$ content of the species (Normore \& Brown, 1970). However, the $G+C$ contents of these loci from Serratia do not reflect the overall G + C content of the Serratia genome $(59 \mathrm{~mol} \%$; Normore \& Brown, 1970 ), indicating that the nucleotide content of these genes is highly conserved across enteric species and, as noted by Sharp (1990), the selective forces reflected in codon usage bias are not constrained by mutational pressures towards high $\mathrm{G}+\mathrm{C}$ content. The sequences from each species display high levels of codon usage bias (Table 1), as calculated by the codon adaptation index (CAI) of Sharp \& Li (1987b). Although the CAI is based on the pools of preferred codons estimated from the $E$. coli genome, these data suggest that preferred codons are probably similar among divergent enteric species, and are not significantly altered by selective constraints on overall genomic nucleotide content.

Table 2 shows that there is little sequence variation among conspecific strains. Only E. vulneris ATCC 29943 is very divergent from other strains typed to this species. This result is not unexpected, as total DNA relatedness is reported as being significantly lower between this and other putative E. vulneris isolates (Brenner et al., 1982b). Therefore, with the exception of two representative strains of E. vulneris (ATCC 29943 and ATCC 33821), DNA sequences from single strains of each species were 
Nucleotide sequences at the gap locus

72

99

126

ECO ATTGTTTTC CGTGCTGCT CAGAAACGT TCTGACATC GAGATCGTT GCAATCAAC GACCTGTTA GACGCTGAT TACATGGCA TACATGCTG AAATATGAC TCCACTCAC

bl1

Eb12

Wb13

the 1

the 2

Evul

Evu2

Evu3

Efel

Efe2

Efe 3

Sty

cfr

Kpn

Eae

sod
TGTTTTC CGTGCTGCT CAGAAACG

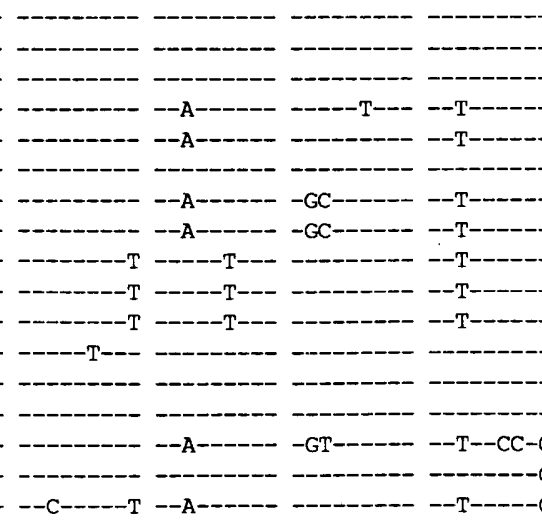

207

180

ECO GGCCGTTTC GACGGTACC GTTGAAGTG AAAGACGGT CATCTGATC GTTAACG

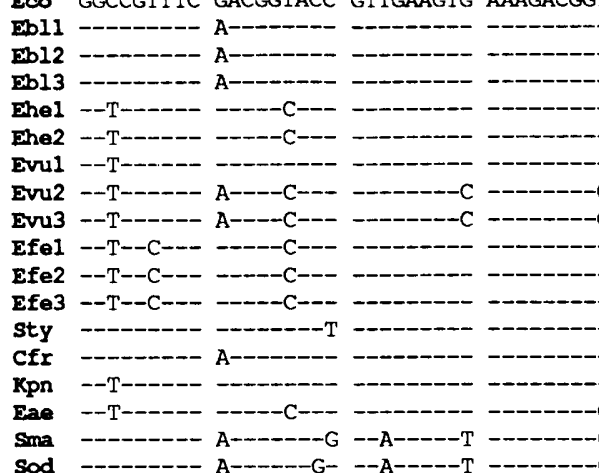

288

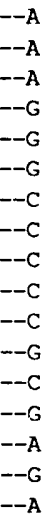

$---T$

- -

------- T

$------T$

$--\cdots--G$

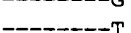

-

$------$

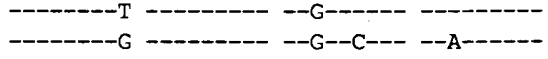

234

261

GT AAAAAATC CGTGTTACC GCTGAACGT GATCCGGCT AACCTGAAA TGGGACGAA
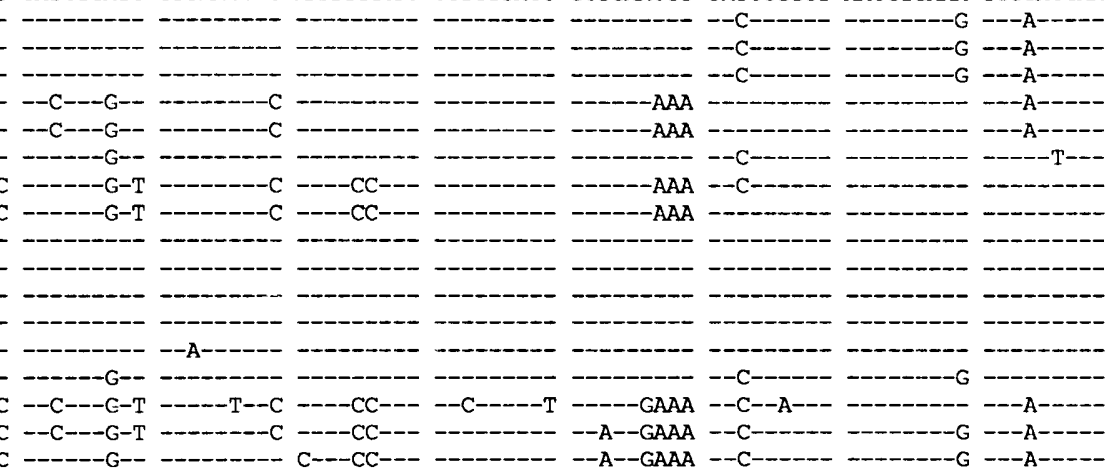

342

369

E00 GITGGTGTT GACGTTGTC GCTGAAGCA ACTGTTCTG TTCCTGACT GACGAAACT GCTCGTAAA CACATCACC GCTGGTGCG AAAAAGGTG GTTATGACT GGTCCGTCT

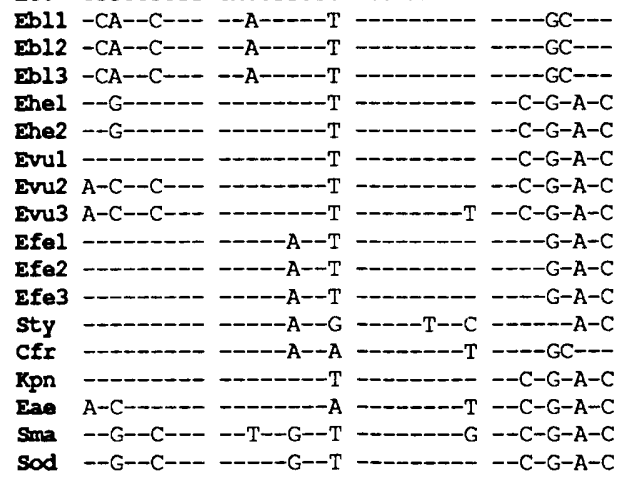

בים

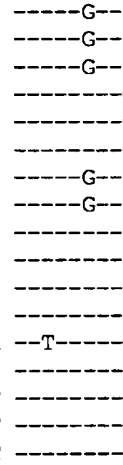

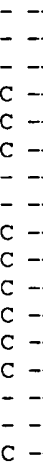

396

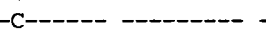

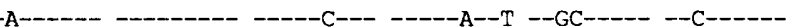

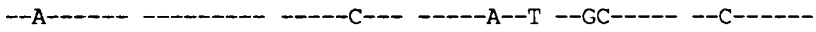

(-)-

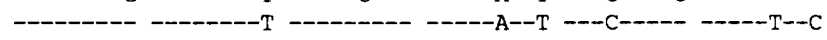
--- ----

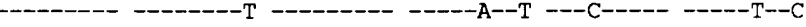

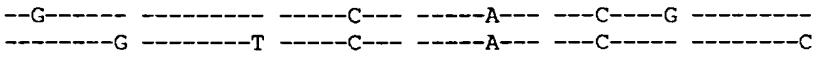
--A----- -------T --G------ --G--A--T ---C----- -----T--C

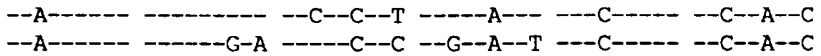

423

450

477

Eco AAAGACAAC ACTCCGATG TTCGTTAAA GGCGCTAAC TTTGACAAA TATGCTGGC CAGGACATC GTTTCCAAC GCTTCCTGC ACCACCAAC TGCCTGGCT CCGCTGGCT

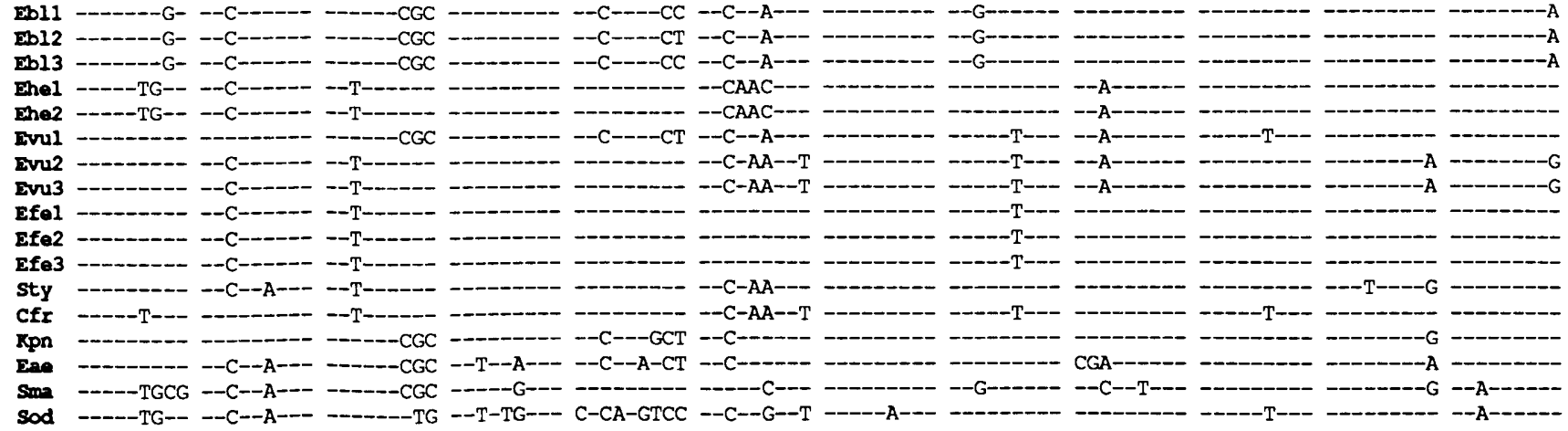


504

531

558

ED AAAGTTATC AACGATAAC TTCGGCATC ATCGAAGGT CTGATGACC ACCGTTCAC GCTACTACC GCTACTCAG AAAACCGTT GATGGCCCG TCTCACAAA GACTGGCGC \$bl1 -

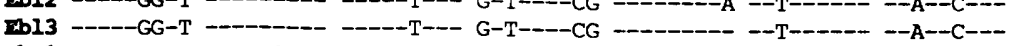

Whe

Tru1 -

Evu2 - -

Iffel

Ife2

Ife3

Sty

Kpn

Kan

$\sin$
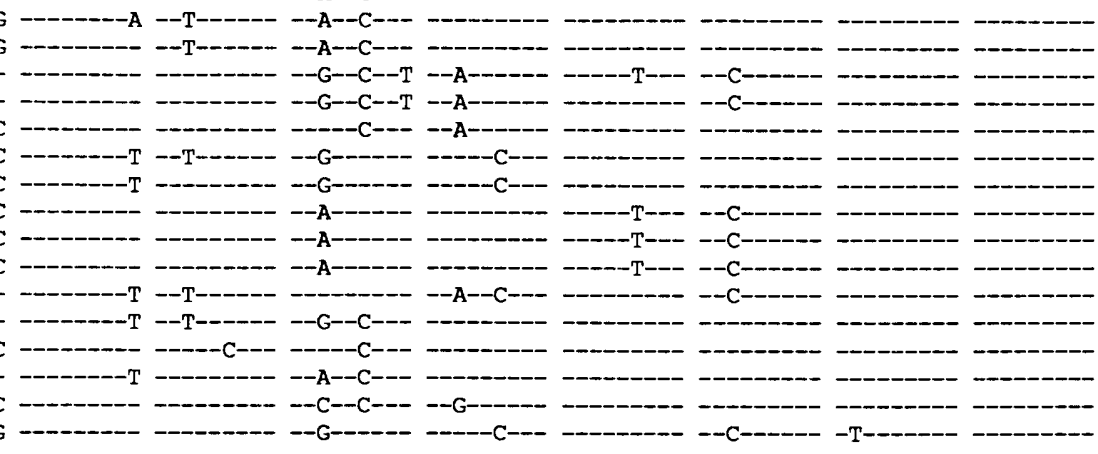

612

639

666

Eo GGCGGCCGC GGCGCTTCC CAGAACATC ATCCCGTCC TCTACCGGT GCTGCTAAA GCTGTAGGT AAAGTACTG CCGGAACTG AATGGCAAA CTGACTGGT ATGGCGTTC
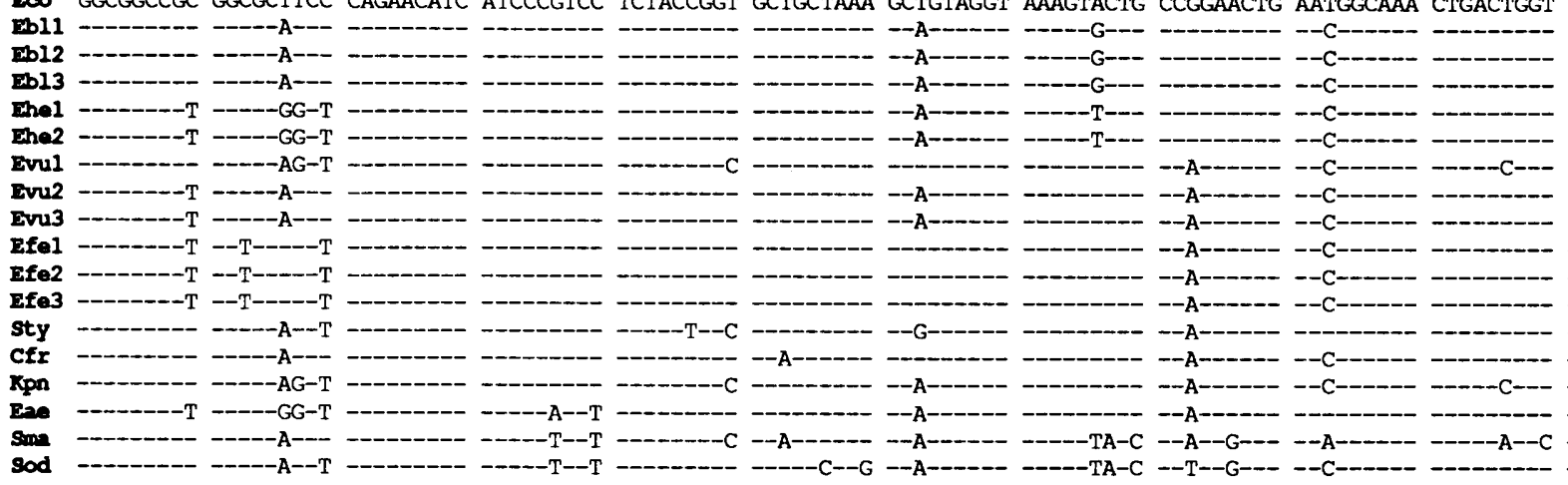

720

747

774

801

Eo CGCGTTCCG ACCCCGAAC GTATCTGTA GTTGACCTG ACCGTTCGT CTGGAAAAA GCTGCAACT TACGAGCAG ATCAAAGCT GCCGTTAAA GCTGCTGCT GAAGGCGAA

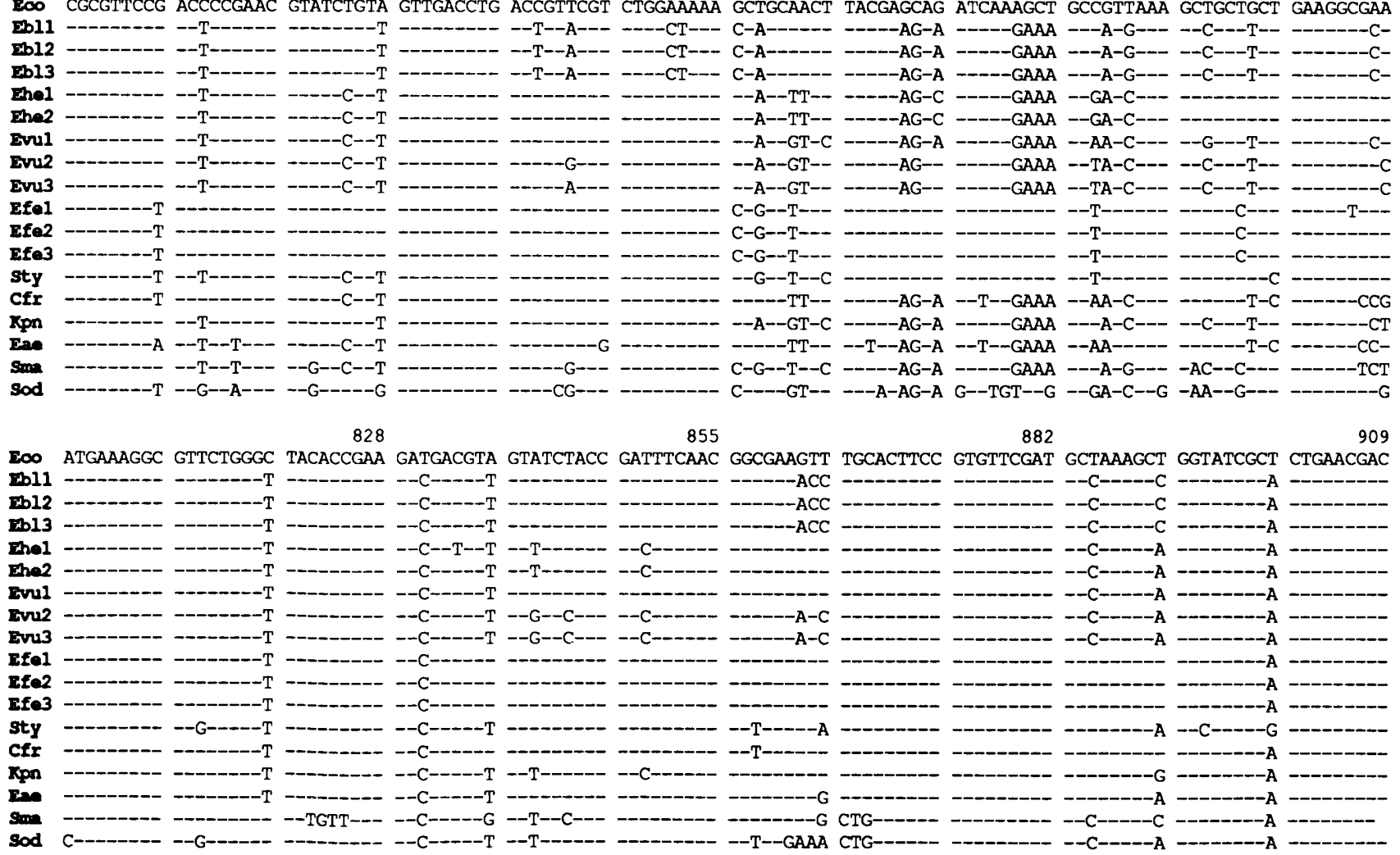




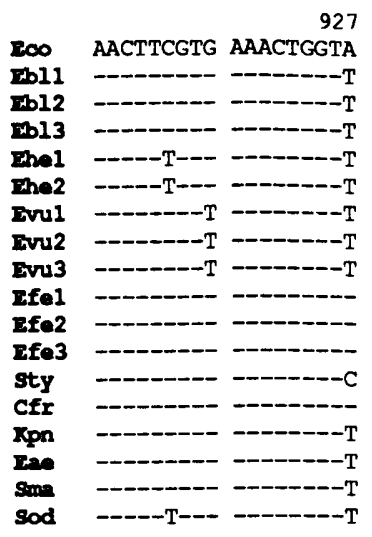

Nucleotide sequences at the ompA locus

324

351

378

399

ID CTGACCGCT AAACTGGGT TACCCAATC ACTGACGAC CTGGACATC TACACTCGT CTGGGTGGC ATGGTATGG CGTGCAGAC ACTAAATCC AACGTTTAT GGTO00000

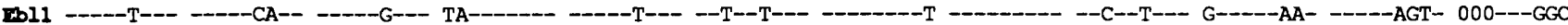



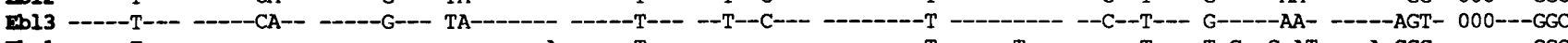

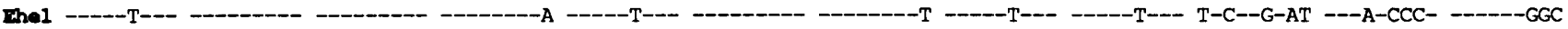

Whe2 -----T--- --

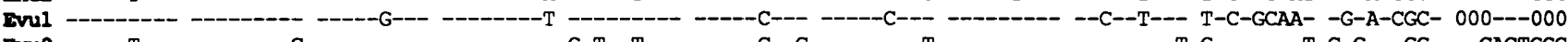

Evu2 ---T-- ---C -- - -

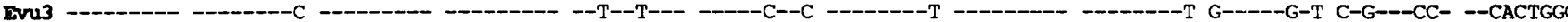

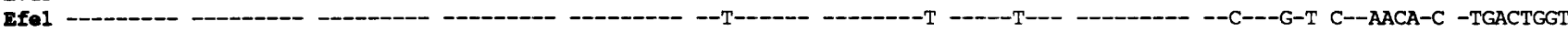

Efe2 - - - - - - - - - - - - - - -

Efe3

Sty

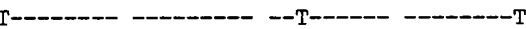

-

Cfr - -

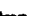

$\operatorname{sod}$

$--G----------A-C$ - - - TCAACCGGC

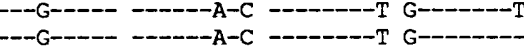

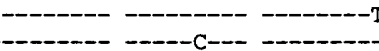

$--\mathrm{A}-\mathrm{C}--$

417

444

T-C-GCAA- -G-A-CGC- O00----

T----G-T ---TACGGC C--ACTGGC

E00 000000000 AAAAACCAC GACACCGGC GTTTCTCCG GTCTTCGCT GGCGGTGTT GAGTACGCG ATCACTCCT GAAATCGCT ACCCGTCTG GAATACCAG TGGACGAAC

W11 GGCGATCGT -GC--_-- --T-_-_-

W12 GGCGACCGT -GC----- --T---.- -

ED13 GGCGACCGT -GC-.-- --T-_-_ -

Whal GCGTCTTTC ---G-T--T --.----T -----C--A --A------ -----CC-G ----GG--A G-T--C-G- --C----- --

The2 GCGTCTTTC ---G-T--T -------T -----C--A --A----- -----CC-G ----GG--A G-T--C-G- --C----- --

Ful1 GGCGAC--- 000----- --------- -----C--A --A------ -----C--- ----GG--T --G--C-G- --C--A--- ---

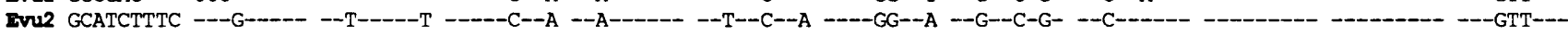

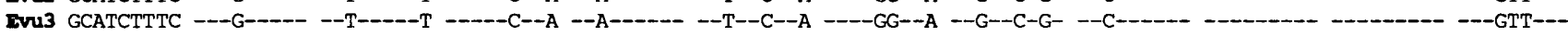

zfel GAATCTGAC ---

$\mathbf{z} \mathbf{2} 3$ GAATCTGAG ----- --T---

Sty CCGTCTACT ---

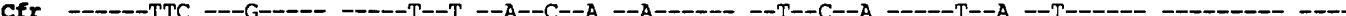

Xpn GTTTCCCGT -GCG-A--- -----T--- --.--C--A --A--T--- -----C--A ----GG--T G-T-D--G- --C------ -.--

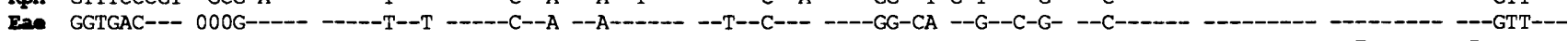

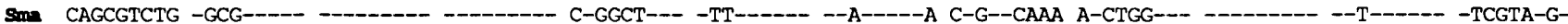

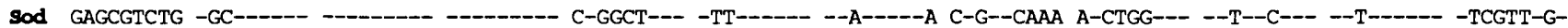

525

552

579

603

EO AACATCGGT GACGCACAC ACCATCGGC ACTCGTCCG GACAACGGC ATGCTGAGC CTGGGTGTT TCCTACCGT TTCGGTCAG GGCGAGGCA O00GCTCCA GTAGTTGCT

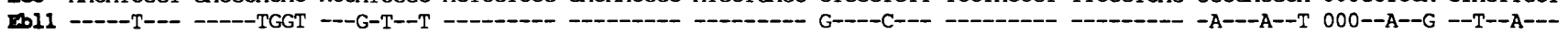



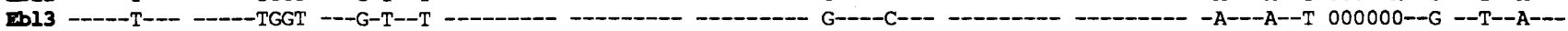

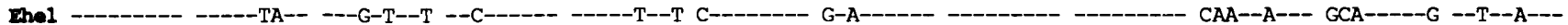

Whe2 - - - - - TA-- - T-T--T --C-

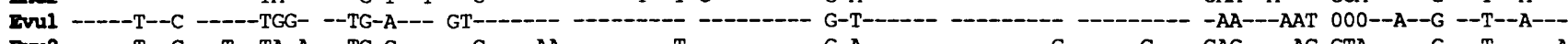

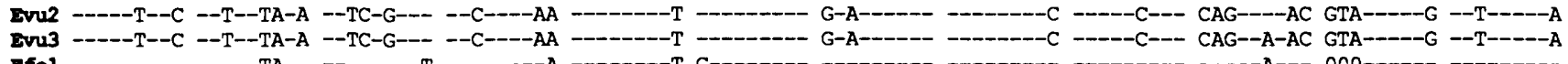

Ifel - -

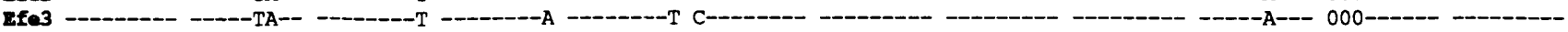

Sty - --T--CA-- -- - -

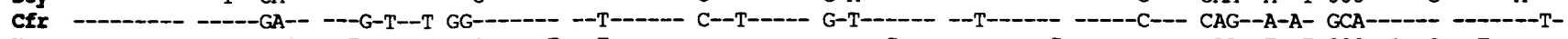

Xpn - -

Sev - - - - - - -

sod - - 
630

657

684

711

ED CCGGCTCCA GCTCCGGCA CCGGAAGTA CAGACCAAG CACTTCACT CTGAAGTCT GACGTTCTG TTCAACTTC AACAAAGCA ACCCTGAAA CCGGAAGGT CAGGCTGCI

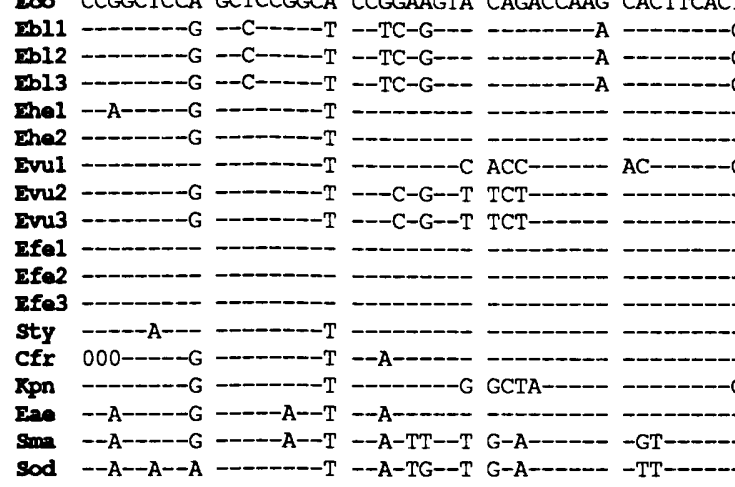

738

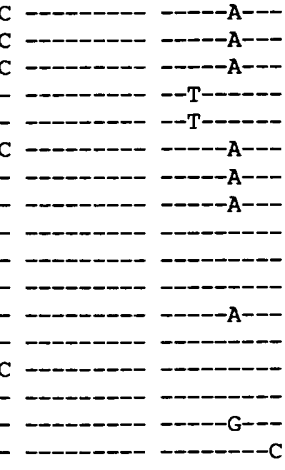

765

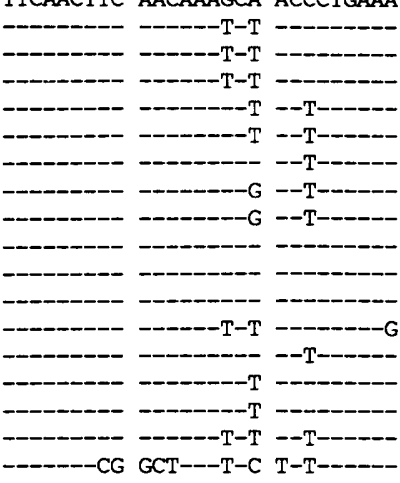

792

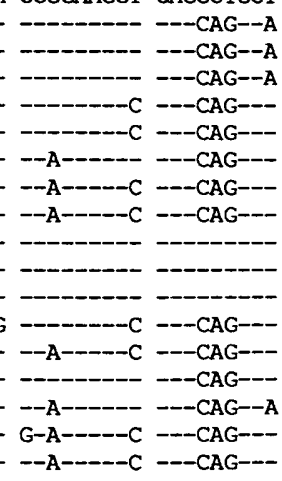

819

Eo CTGGATCAG CTGTACAGC CAGCTGAGC AACTTGGAT CCGAAAGAC GGTTCCGTA GTTGTTCTG GGTTACACC GACCGCATC GGTTCTGAC GCTTACAAC CAGGGTCTG

שb11 -

ख012 -

mbl3 -

Thel -

Eve2 -

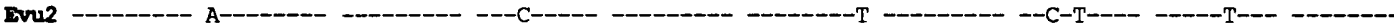

Evu3 -

Efel

Bfe2

Efe3

sty

Kpn

Sme

Sod

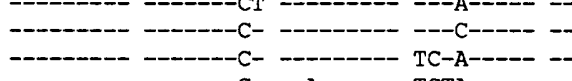

846

ED TCCGAGCGC CGTGCTCAG TCTGTTGTT GATTACCTG ATCTCCAAA GGTATCCCG GCAGACAAG ATCTCCGCA CGTGGTATG GGCGAATCC AACCCGGTT ACTGGCAAC

\b11 ---C---AG ------ --C----- --C----- G-A--T--- -------- ----GT--A ---A-T--T -AG--CCA- --T-----T -------- --C--T---

Ebl2 --C-DAG --

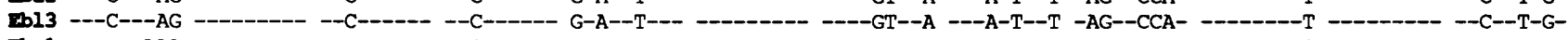

Ehel

Eve2 -

Evu2 -

TYu3 - - - -

Efel

Efe2

Efe3

sty

- - - - - - - - - - -

Xpn - T-- AAA

Fas - T---AAA

$\sin --T-A C A A$

$$
-\mathrm{T}-
$$

$$
\text { - }
$$

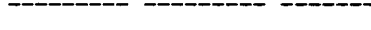

951

972

999

DO0 ACCTGTGAC AACGTGAAA CAGO0OCGT GCTGCAO00 O00CTGATC GACTGCCTG GCTCCGGAT CGTCGCGTA GAGATCGAA GTTAAAGGTATC

w11 -

El2 -

Ebl3 - -

The 1 -

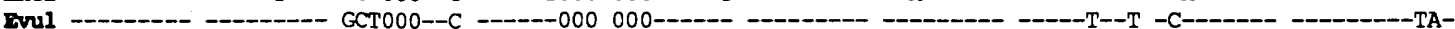

Evv2 --_-_- - -

Evu3 -

Efe2

Efe3

Sty

Ken

$\ln$

$-1-000--$

$-000000$

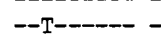

CG-T

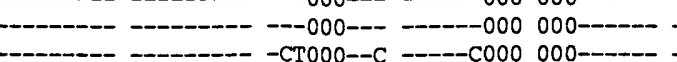

- - - - - CCT000-C -

- $\mathrm{T}-\mathrm{T}-\mathrm{C}-\mathrm{C}$

- - - - -

$---G-$ T--000-- TCTGGC--

$--C 000000$

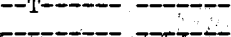

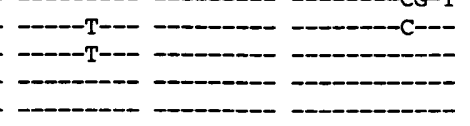

$\operatorname{sod}$

TAAC AAA-A-D- -T-D-- -

000----G- T--000--- AACGGT--- ---A-CAAA GCA-A---- --A----- --G--TA-C

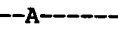


analysed further. The phylogenetic relationships among isolates were analysed for each gene using a maximum parsimony algorithm (PAUP). In both cases, a single most parsimonious tree was found. Moreover, the branching orders for the gap and $o m p A$ loci were congruent. This common tree is presented in Fig. 2. The relative branching order of the species was tested using the Felsenstein test on four-taxon subgroups, assuming a stochastic molecular clock (Felsenstein, 1985). This test allows a statistical comparison of the three possible relationships between four taxa, and confirmed all branch points (the resolution of relationships between E. vulneris, E. hermannii and Enterobacter aerogenes required the elimination of synonymous changes from the data set).

Since the sequences of gap and $o m p A$ both define a single phylogenetic tree, it is likely that this genealogy accurately reflects the evolutionary relationships among bacterial lineages. More specifically, it is unlikely that horizontal transfer of both genes between enteric species (requiring independent transfer of the two loci or conjugative transfer of a portion of the bacterial chromosomes exceeding $1000 \mathrm{~kb}$ ) has occurred. In addition, the sequences from independent isolates typed as the same species are quite similar, suggesting that the original classification of these strains within a species, based on total DNA relatedness and overall phenotypic similarity, is valid. The overall branching order and pattern of divergence among taxa (E. coli, Sal. typhimurium, Klebsiella pneumoniae, Ent. aerogenes, and Serr. marcescens) reflected by these genes is similar to earlier assessments of their genetic relationships based on a combination of phenotypic and genetic characters (Brenner \& Falkow, 1971; Cocks \& Wilson, 1972; Ochman \& Wilson, 1987).

Species of Salmonella are traditionally considered to be those most closely related to $E$. coli. If Escherichia were considered to represent a monophyletic group, additional species of Escherichia should be more closely related to E. coli than is Salmonella. From the phylogeny presented in Fig. 2, it is apparent that the genus Escherichia is not a monophyletic group. That is, neither the ancestor of all Escherichia species, nor all its descendent taxa, belong to that genus. The Felsenstein statistics presented in Table 3 (Felsenstein, 1985) support the hypothesis that only

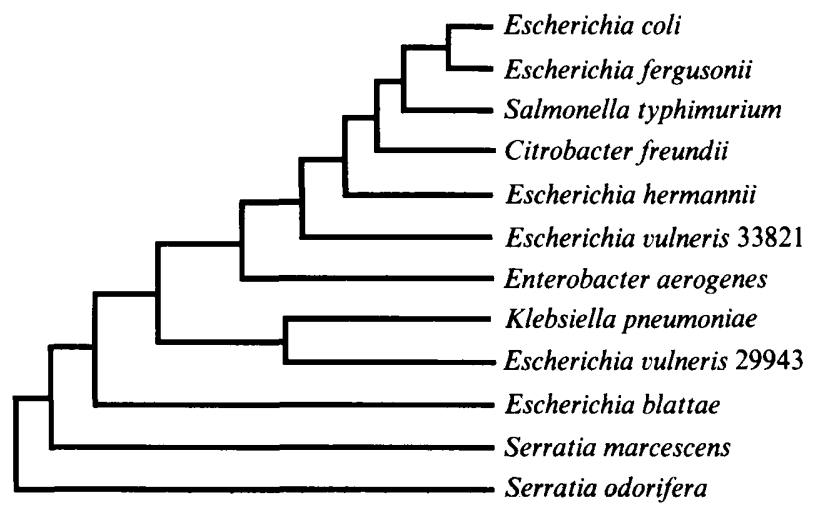

Fig. 2. Phylogeny of selected enteric bacteria based on DNA sequences from the gap and ompA loci, generated by a maximum parsimony algorithm. Taxon designations refer to strains listed in Table 1. The phylogeny was rooted using the nucleotide sequence of the gap locus from a strain of Morganella morganii (H. Ochman, unpublished results).

E. coli and E. fergusonii are congeneric species and diverged following the split of Escherichia from Salmonella $(P<0.05)$. However, this hypothesis is rejected for $E$. blattae, $E$. hermannii, and both genotypes of $E$. vulneris $(P<0.05)$. The data suggest that these Escherichia species are more distantly related to $E$. coli than is Salmonella and should be placed in alternative genera. Since bacterial genera should reflect monophyletic groups, the putative species of Escherichia must be reclassified or this genus would encompass species of Salmonella, Citrobacter, Enterobacter and Klebsiella. In a similar manner, Serr. odorifera was classified according to phenotypic characters (Grimont et al., 1978). As is evident from Fig. 2, such classification does not allow definition of the genus Serratia as a monophyletic group.

The DNA hybridization data of Brenner and coworkers (Brenner et al., 1982a,b) also indicate that both $E$. hermannii and E. vulneris are distantly related to E. coli. However, neither species could be unambiguously classified into any one genus based on DNA hybridization studies. The DNA hybridization data are summarized in Table 4. In the cases of $E$. hermannii and $E$. vulneris, metabolic characteristics implied close relationships to $E$. coli and to one another. These species were classified in the genus Escherichia on the basis of metabolic profiles, despite the data from DNA hybridiz-

Fig. 1 (on preceding pages). Nucleotide sequences of the gap and ompA loci from enteric bacteria. Taxa designations are: Eco, Escherichia coli; Ebll, E. blattae ATCC 29907; Ebl2, E. blattae ATCC 33429; Ebl3, E. blattae ATCC 33430; Ehe1, E. hermannii ATCC 33650; Ehe2, E. hermannii ATCC 33652; Evu1, E. vulneris ATCC 29943; Evu2, E. vulneris ATCC 33821; Evu3, E. vulneris ATCC 33822; Efe1, E. fergusonii ATCC 35469; Efe2, E. fergusonii ATCC 35471; Efe3, E. fergusonii ATCC 35472; Sty, Salmonella typhimurium; $\mathrm{Cfr}$, Citrobacter freundii; Kpn, Klebsiella pneumoniae; Eae, Enterobacter aerogenes; Sma, Serratia marcescens; Sod, Serr. odorifera. Nucleotide numbering corresponds to positions in the published $E$. coli sequence. Nucleotides unchanged from the $E$. coli sequence are designated as '-', and nucleotide deletions are designated as ' 0 '. 


\section{Table 3. Summary of statistics from Felsenstein's test}

Taxon designations for potential phylogenies are: Eco, Escherichia coli K12; Sty, Salmonella typhimurium LT2; OUT, outgroup specified for each test; ${ }^{* *}$, test species specified. Statistic ' $\mathrm{C}$ ' is the number of informative characters supporting each tree; statistic ' $\mathrm{S}$ ' corresponds to the number of steps separating the best tree from the next-best tree. ${ }^{*}$, Measures which are statistically significant at $P<0 \cdot 05$. E. vulneris 'a' and 'b' are strains ATCC 29943 and ATCC 33821 , respectively.

\begin{tabular}{|c|c|c|c|c|c|c|}
\hline \multirow[b]{2}{*}{ Test } & \multicolumn{6}{|c|}{ Potential phylogeny: } \\
\hline & Eco ${ }^{*}$ & Sty OUT & C & OUT & Eco & Sty OUT \\
\hline $\begin{array}{l}\text { E. blattae, gap } \\
\text { OUT: } K . \text { pneumoniae }\end{array}$ & 11 & - & 2 & - & $26^{*}$ & $15^{*}$ \\
\hline $\begin{array}{l}\text { E. blattae, ompA } \\
\text { OUT: Serr. marcescens }\end{array}$ & 7 & - & 9 & - & $21^{*}$ & $12^{*}$ \\
\hline $\begin{array}{l}\text { E. fergusonii, gap } \\
\text { OUT: E. vulneris a }\end{array}$ & $14^{*}$ & $7^{*}$ & 5 & - & 7 & - \\
\hline $\begin{array}{l}\text { E. fergusonii, ompA } \\
\text { OUT: } K \text {. pneumoniae }\end{array}$ & $26^{*}$ & $20^{*}$ & 6 & - & 4 & - \\
\hline $\begin{array}{l}\text { E. hermannii, gap } \\
\text { OUT: Ent. aerogenes }\end{array}$ & 4 & - & 6 & - & $26^{*}$ & $20^{*}$ \\
\hline $\begin{array}{l}\text { E. hermannii, omp A } \\
\text { OUT: } C \text {. freundii }\end{array}$ & 9 & - & 10 & - & $19^{*}$ & $9^{*}$ \\
\hline $\begin{array}{l}\text { E. vulneris a, gap } \\
\text { OUT: Ent. aerogenes }\end{array}$ & 3 & - & 6 & - & $36^{*}$ & $30^{*}$ \\
\hline $\begin{array}{l}\text { E. vulneris a, ompA } \\
\text { OUT: E. hermannii }\end{array}$ & 8 & - & 10 & - & $18^{*}$ & $8^{*}$ \\
\hline $\begin{array}{l}\text { E. vulneris b, gap } \\
\text { OUT: } K \text {. pneumoniae }\end{array}$ & 1 & - & 3 & - & $36^{*}$ & $33^{*}$ \\
\hline $\begin{array}{l}\text { E. vulneris b, ompA } \\
\text { OUT: Ent. aerogenes }\end{array}$ & 6 & - & 2 & - & $30^{*}$ & $24^{*}$ \\
\hline
\end{tabular}

ation studies. Our data support the original DNA hybridization data (Brenner et al., 1982a,b) and suggest a reconsideration of the generic placement of the taxa.

The DNA sequence data summarized in Table 2 show that E. vulneris ATCC 29943 is not closely related to other strains typed as E. vulneris and the phylogenetic placement of $E$. vulneris strains indicate that $E$. vulneris ATCC 29943 and other E. vulneris strains are not conspecific. The Felsenstein statistics support the hypothesis that $E$. vulneris ATCC 29943 is closely related to $K$. pneumoniae (for gap and ompA, 36/40 and 30/38 sites, respectively, support that grouping; $P<0.05$ ). Therefore, while biochemical characteristics and total DNA relatedness suggest that these strains may be conspecific, the genetic evidence presented here does not support this hypothesis. Rather, the DNA data suggest that E. vulneris ATCC 29943 be placed in the genus Klebsiella, and not be considered a strain of the taxon E. vulneris, as defined by the type strain ATCC 33821 .

Attempts to discern the evolutionary relationships among enteric bacteria have utilized a wide range of characters, including immunological relationships (Cocks \& Wilson, 1972), metabolic pathways (Ahmad et al., 1990; Jensen, 1985), DNA hybridization (Brenner, 1978; Brenner \& Falkow, 1971) and standard biochemical and enzymic profiles (Brenner, 1981, 1984; Edwards \& Ewing, 1962). An underlying weakness of these methods is the inability to directly measure the genetic relationships between species. Alternatively, an assessment of homologous DNA sequences among species not only resolves fine-scale taxonomic relationships but the data allow an analysis of gene evolution within the context of the evolutionary history of the organisms. Although it has been argued that constraints on the evolution of protein and ribosomal RNA molecules preclude their use as taxonomic tools (Meyer $e t$ $a l ., 1986$ ), one can statistically test phylogenies inferred from these macromolecules.

From published sequence data, it is possible to design oligonucleotide primers that will allow PCR amplification of homologous genes from distantly related taxa. This approach has been applied to examine the 
Table 4. Comparison of DNA hybridization and nucleotide divergences of Escherichia coli and other enteric bacteria

\begin{tabular}{|c|c|c|c|}
\hline \multirow[b]{2}{*}{ Strain } & \multirow{2}{*}{$\begin{array}{c}\text { DNA } \\
\text { hybridization* }\end{array}$} & \multicolumn{2}{|c|}{$\begin{array}{c}\text { Total } \\
\text { changes } \dagger\end{array}$} \\
\hline & & gap & ompA \\
\hline Escherichia coli $\mathrm{K} 12$ & 100 & 0 & $\mathbf{0}$ \\
\hline Escherichia fergusonii ATCC 35469 & 60 & 43 & 25 \\
\hline Salmonella typhimurium LT2 & 45 & 55 & 68 \\
\hline Citrobacter freundii OS60 & 50 & 62 & 78 \\
\hline Escherichia hermannii ATCC 33650 & 31 & 81 & 77 \\
\hline Escherichia vulneris ATCC 33821 & 35 & 94 & 92 \\
\hline Klebsiella pneumoniae LD199 & 38 & 71 & 95 \\
\hline Enterobacter aerogenes E482 & 37 & 107 & 93 \\
\hline Escherichia blattae ATCC 29907 & 29 & 75 & 104 \\
\hline Serratia marcescens ATCC 13880 & 24 & 128 & 145 \\
\hline$S \ddagger$ & & $22 \S$ & $20 \S$ \\
\hline
\end{tabular}

* Percentage association of genomic DNA at $60^{\circ} \mathrm{C}$ (Brenner \& Falkow, 1971; Brenner et al., 1982a, b; Farmer et al., 1983).

$\dagger$ Total number of substitutions between $E$. coli and the given taxon at the respective locus.

$\ddagger$ The Kendall rank test $S$ statistic testing an inverse correlation between the total number of substitutions between $E$. coli and the other enteric strains at each locus and their percentage reassociation during DNA hybridization. $\S$ denotes a significant negative correlation $(P<0.05)$.

evolutionary relationships among metazoans based on cytochrome $b$ oxidase genes of mitochondrial DNA (Kocher et al., 1989) and could be extended to include any group of organisms. The only requirement in using macromolecules to infer accurate phylogenies is that their sequences have sufficient variation to discern evolutionary relationships but are minimally affected by convergent events. We have shown that genetic loci experiencing selection reflected in codon usage bias satisfy these requirements.

Owing to its ubiquitous distribution and conservative evolution, GAPDH would serve as an ideal molecule for inferring fine-scale phylogenetic relationships among organisms not readily distinguished by rDNA sequences. Aside from the eighteen gap genes from enteric bacteria reported in this paper, the nucleotide sequences of GAPDH-encoding genes have been determined for some 40 taxa, including representatives from each urkingdom (Doolittle et al., 1990). Using a large set of GAPDHencoding sequences, Doolittle et al. (1990) postulated that the high degree of similarity between the E. coli gap gene and eukaryotic GAPDH-encoding sequences resulted from a horizontal transfer event introducing a eukaryotic gap homologue into the bacterial genome (see also Martin \& Cerff, 1986). Other eubacterial lineages, notably Bacillus stearothermophilus, Thermus aquaticus, Zymomonas mobilis and the cyanobacterial-derived chloroplasts, harbour gap genes distinct from those of
$E$. coli and eukaryotes. The gap sequences presented in this paper clearly establish that any horizontal transfer event must have occurred prior to the divergence of the enteric bacteria. Phylogenies based on the gap and ompA sequences are congruent (Fig. 2), indicating that these genes were not subject to horizontal transfer processes. Moreover, a second potential GAPDH-encoding locus has been identified in E. coli (Alefounder \& Perham, 1989) which is similar to the non-enteric prokaryotic gap genes (Doolittle et al., 1990). To identify the lineage accommodating the initial transfer event, one must determine the sequences of GAPDH-encoding genes from species having diverged from the $E$. coli lineage prior to Serr. odorifera, yet following the divergence of the purple bacterium $Z$. mobilis.

While DNA sequence data may be useful in the generic placement of novel species, a revision of the taxonomy of extant enteric species would cause considerable confusion. The long-standing practice of classifying aberrant bacterial strains as novel species without regard to evolutionary history (e.g. the classification of nonlactose-fermenting strains of $E$. coli in Shigella) has constrained the ability of classification to reflect phylogeny. The advent of PCR and rapid DNA sequencing has allowed the elucidation of fine-scale phylogenetic relationships among bacterial species, which is necessary to examine the evolution of their genomes.

We thank J. P. Carulli, R. F. DuBose, D. E. Krane and A. Larson for aid and helpful discussions, Carl Woese for sharing unpublished data, and the laboratories of Doug Berg and Staffan Normark for providing bacterial strains. This work was supported by grant GM 40322 (D. L. H.) and GM 40995 (H.O.) from the National Institute of Health.

\section{References}

Ahmad, S., Weisburg, W. G. \& Jensen, R. A. (1990). Evolution of aromatic amino acid biosynthesis and application to the fine-tuned phylogenetic positioning of enteric bacteria. Journal of Bacteriology 172, 1051-1061.

Alefounder, P. R. \& Perham, R. N. (1989). Identification, molecular cloning and sequence analysis of a gene cluster encoding the Class II fructose 1,6-biphosphate aldolase, 3-phosphoglycerate kinase and a second glyceraldehyde 3-phosphate dehydrogenase of Escherichia coli. Molecular Microbiology 3, 723-732.

BACHMANN, B. J. (1990). Linkage map of Escherichia coli K-12, edition 8. Microbiological Reviews 54, 130-197.

BECK, E. \& BREMER, E. (1980). Nucleotide sequence of the gene ompA coding the outer membrane protein $\mathrm{II}^{*}$ of Escherichia coli $\mathrm{K}-12$. Nucleic Acids Research 8, 3011-3024.

Bergström, S., Lindberg, P., Olsson, O. \& Normark, S. (1983). Comparison of the overlapping frd and ampC operons of Escherichia coli with the corresponding DNA sequences in other gram-negative bacteria. Journal of Bacteriology 155, 1297-1305.

Branlant, G. \& Branlant, C. (1985). Nucleotide sequence of the Escherichia coli gap gene: different evolutionary behavior of the NAD ${ }^{+}$-binding domain and of the catalytic domain of the D-glyceraldehyde-3-phosphate dehydrogenase. European Journal of Biochemistry 150, 61-66. 
Branlant, C., Oster, T. \& Branlant, G. (1989). Nucleotide sequence determination of the DNA region coding for Bacillus stearothermophilus glyceraldehyde-3-phosphate dehydrogenase and of the flanking DNA regions required for its expression in Escherichia coli. Gene $75,145-155$.

Braun, G. \& Cole, S. T. (1984). DNA sequence analysis of the Serratia marcescens ompA gene: implication for the organisation of an enterobacterial outer membrane protein. Molecular and General Genetics 195, 321-328.

BRENNER, D. J. (1978). Characterization and clinical identification of Enterobacteriaceae by DNA hybridization. Progress in Clinical Pathology 7, 71-117.

BRENNER, D. J. (1981). Introduction to the family Enterobacteriaceae. In The Prokaryotes: a Handbook on Habitats, Isolation and Identification of Bacteria, vol. 2, pp. 1105-1127. Edited by M. P. Starr, H. Stolp, H. G. Trüper, A. Balows \& H. G. Schlegel. Berlin: Springer-Verlag.

BRENNER, D. J. (1984). Enterobacteriaceae. In Bergey's Manual of Systematic Bacteriology, vol. 1, pp. 408-420. Edited by N. R. Krieg \& J. G. Holt. Baltimore: Williams \& Wilkins.

BRENNER, D. J. \& FALKow, S. (1971). Molecular relationships among members of the Enterobacteriaceae. Advances in Genetics 16, 81-118.

Brenner, D. J., Farmer, J. J., III, Fanning, G. R., STeigerwalt, A. G., KlykKen, P., Wathen, H. G., Hickman, F. W. \& Ewing, W. H. (1978). Deoxyribonucleic acid relatedness of Proteus and Providencia species. International Journal of Systematic Bacteriology 28, 269-282.

Brenner, D. J., Steigerwalt, A. G., Gorman, G. W., Weaver, R. E., Feeley, J. C., Cordes, L. G., Wilkinson, H. W., Patton, C., Thomason, B. M. \& Lewallen Sasseville, K. R. (1980). Legionella bozemanii sp. nov. and Legionella dumoffii sp. nov.: classification of two additional species of Legionella associated with human pneumonia. Current Microbiology 4, 111-116.

Brenner, D. J., Davis, B. R., Steigerwalt, A. G., Riddle, C. F., MCWhorter, A. C., Allen, S. D., Farmer, J. J., III, SAitoh, Y. \& FANNING, G. R. (1982a). Atypical biogroups of Escherichia coli found in clinical specimens and description of Escherichia hermannii sp. nov. Journal of Clinical Microbiology 15, 703-713.

Brenner, D. J., McWhorter, A. C., Leete KnUtson, J. K. \& SteIGERWALT, A. G. (1982b). Escherichia vulneris: a new species of Enterobacteriaceae associated with human wounds. Journal of Clinical Microbiology 15, 1133-1140.

Burgess, N. R. H., MCDermott, S. N. \& Whiting, J. (1973). Aerobic bacteria occurring in the hind-gut of the cockroach, Blatta orientalis. Journal of Hygiene 71, 1-7.

Cocks, - G. T. \& WiLson, A. C. (1972). Enzyme evolution in the Enterobacteriaceae. Journal of Bacteriology 110, 793-802.

Doolittle, R. F., Feng, D. F., Anderson, K. L. \& Alberrro, M. R. (1990). A naturally occurring gene transfer from a eukaryote to a prokaryote. Journal of Molecular Evolution 31, 383-388.

EDWARDS, P. R. \& EWING, W. H. (1962). Identification of Enterobacteriaceae. Minneapolis: Burgess

FARMER, J. J., III, FANNING, G. R., DAvis, B. R., O'HARA, C. M., Riddle, C., HickMAN-BrenNer, F. W., AsBuRy, M. A., LoWERY, V. A., III \& BRENNER, D. J. (1985). Escherichia fergusonii and Enterobacter taylorae, two new species of Enterobacteriaceae isolated from clinical specimens. Journal of Clinical Microbiology 21, 77-81.

Felsenstein, J. (1985). Confidence limits on phylogenies with a molecular clock. Systematic Zoology 34, 152-161.

Freudl, R. \& Cole, S. T. (1983). Cloning and molecular characterization of the ompA gene from Salmonella typhimurium. European Journal of Biochemistry 134, 497-502.

Galliard, C. \& Strauss, F. (1990). Ethanol precipitation of DNA with linear polyacrylamide as carrier. Nucleic Acids Research 18, 378.
Grimont, P. A. D., Grimont, F., Richard, C., Davis, B. R., Steigerwalt, A. G. \& Brenner, D. J. (1978). Deoxyribonucleic acid relatedness between Serratia plymuthica and other Serratia species, with a description of Serratia odorifera sp. nov. (type strain: ICPB 3995). International Journal of Systematic Bacteriology 28, 453-463.

JENSEN, R. A. (1985). Biochemical pathways can be traced backward through evolutionary time. Molecular Biology and Evolution 2, 92-108.

Kocher, T. D., Thomas, W. K., Meyer, A., EdWards, S. V., PäÄBo, S. V., Villablanca, F. X. \& Wilson, A. C. (1989). Dynamics of mitochondrial DNA evolution in animals: amplification and sequencing with conserved primers. Proceedings of the National Academy of Sciences of the United States of America 86, 6196-6200.

Martin, W. \& CerfF, R. (1986). Prokaryotic features of a nucleusencoded enzyme. European Journal of Biochemistry 159, 323-331.

Meyer, T. E., Cusanovich, M. A. \& Kamen, M. D. (1986). Evidence against the use of bacterial amino acid sequence data for construction of all inclusive phylogenetic trees. Proceedings of the National Academy of Sciences of the United States of America 83, 217-220.

NORMORE, W. M. \& BRown, J. R. (1970). Guanine plus cytosine $(\mathrm{G}+\mathrm{C})$ composition of bacteria. In Handbook of Biochemistry: Selected Data for Molecular Biology, 2nd edn, pp. H24-H74. Edited by H. A. Sober. Cleveland: The Chemical Rubber Co.

OChman, H. \& Wilson, A. C. (1987). Evolutionary history of enteric bacteria. In Escherichia coli and Salmonella typhimurium: Cellular and Molecular Biology, pp. 1649-1654. Edited by F. D. Niedhardt and others. Washington, DC: American Society for Microbiology.

OCHMAN, H. \& Wilson, A. C. (1988). Evolution in bacteria: evidence for a universal substitution rate in cellular genomes. Journal of Molecular Evolution 26, 74-86.

Saiki, R. K., Scharf, S., Faloona, F., Mullis, K. B., Horn, G. T., ERLICH, H. A. \& ARNHEIM, N. A. (1985). Enzymatic amplification of $\beta$-globin genomic sequences and restriction site analysis for diagnosis of sickle cell anemia. Science 230, 1350-1354.

Saiki, R. K., Gelfand, D. H., Stoffel, S., Scharf, S. J., Higuchi, R., Horn, G. T., Mullis, K. B. \& ErLich, H. A. (1988). Primer-directed enzymatic amplification of DNA with a thermostable DNA polymerase. Science $239,487-491$.

Sawyer, S., Dykhuizen, D., DuBose, R. F., Green, L., Mutangadura-Mhlanga, T., Wolczyk, D. F. \& Hartl, D. L. (1987). Distribution and abundance of insertion sequences among natural isolates of Escherichia coli. Genetics 115, 51-63.

Sharp, P. M. (1990). Processes of genome evolution reflected by base frequency differences among Serratia marcescens genes. Molecular Microbiology 4, 119-122.

SHARP, P. M. \& LI, W. H. (1987a). Rate of synonymous substitution in enterobacterial genes is inversely related to codon usage bias. Molecular Biology and Evolution 4, 222-230.

Sharp, P. M. \& LI, W. H. $(1987 b)$. The codon adaptation index - a measure of directional synonymous codon usage bias, and its potential applications. Nucleic Acids Research 15, 1281-1295.

Stone, E. M., Rothblum, K. N., Alevy, M. C., Kuo, T. M. \& SCHWARTZ, R. J. (1985). Complete sequence of the chicken glyceraldehyde-3-phosphate dehydrogenase gene. Proceedings of the National Academy of Sciences of the United States of America' 82 , $1628-1632$

Taylor, M. F. J. \& Kreitman, M. E. (1989). PCR amplification of conserved genes from novel genomes with peptide specific primers. Journal of Cellular Biochemistry S13E, 309.

Woese, C. R. (1987). Bacterial evolution. Microbiological Reviews 51, 221-271. 